\title{
Impact of the SARS-CoV-2 pandemic on emergency surgery services-a multi- national survey among WSES members
}

Martin Reichert ${ }^{1 \dagger}$, Massimo Sartelli ${ }^{2 \dagger}$, Markus A. Weigand ${ }^{3}$, Christoph Doppstadt ${ }^{1}$, Matthias Hecker ${ }^{4}$, Alexander Reinisch-Liese ${ }^{5}$, Fabienne Bender ${ }^{1}$, Ingolf Askevold ${ }^{1}$, Winfried Padberg ${ }^{1}$, Federico Coccolini', Fausto Catena ${ }^{7}$, Andreas Hecker ${ }^{1 *}$ (I) and The WSES COVID-19 emergency surgery survey collaboration group

\begin{abstract}
Background: The SARS-CoV-2 pandemic is a major challenge for health care services worldwide. It's impact on oncologic therapies and elective surgery has been described recently, and the literature provides guidelines regarding appropriate elective patient treatment during the pandemic. However, the impact of SARS-CoV-2 pandemic on emergency surgery services has been poorly investigated up to now.

Methods: A 17-item web survey had been distributed to emergency surgeons in June 2020 around the world, investigating the impact of SARS-CoV-2 pandemic on patients and septic diseases both requiring emergency surgery and the time-to-intervention in emergency surgery routine, as well as experiences with surgery in COVID-19 patients.

Results: Ninety-eight collaborators from 31 countries responded to the survey. The majority (65.3\%) estimated the impact of the SARS-CoV-2 pandemic on emergency surgical patient care as being strong or very strong. Due to the pandemic, $87.8 \%$ reported a decrease in the total number of patients undergoing emergency surgery and approximately $25 \%$ estimated a delay of more than $2 \mathrm{~h}$ in the time-to-diagnosis and another $2 \mathrm{~h}$ in the time-to-intervention. Fifty percent make structural problems with in-hospital logistics (e.g. transport of patients, closed normal wards etc.) mainly responsible for delayed emergency surgery and the frequent need (56.1\%) for a triage of emergency surgical patients. $56.1 \%$ of the collaborators observed more severe septic abdominal diseases during the pandemic, especially for perforated appendicitis and severe septic cholecystitis (41.8\% and 40.2\%, respectively). 62.2\% had experiences with surgery in COVID-19-infected patients.

(Continued on next page)
\end{abstract}

\footnotetext{
* Correspondence: andreas.hecker@chiru.med.uni-giessen.de

Federico Coccolini and Fausto Catena are WSES project steering committee representatives.

${ }^{+}$Martin Reichert and Massimo Sartelli contributed equally to this work and shared first authorship.

${ }^{1}$ Department of General, Visceral, Thoracic, Transplant and Pediatric Surgery, University Hospital of Giessen, Giessen, Germany

Full list of author information is available at the end of the article
}

(c) The Author(s). 2020 Open Access This article is licensed under a Creative Commons Attribution 4.0 International License, which permits use, sharing, adaptation, distribution and reproduction in any medium or format, as long as you give appropriate credit to the original author(s) and the source, provide a link to the Creative Commons licence, and indicate if changes were made. The images or other third party material in this article are included in the article's Creative Commons licence, unless indicated otherwise in a credit line to the material. If material is not included in the article's Creative Commons licence and your intended use is not permitted by statutory regulation or exceeds the permitted use, you will need to obtain permission directly from the copyright holder. To view a copy of this licence, visit http://creativecommons.org/licenses/by/4.0/ The Creative Commons Public Domain Dedication waiver (http://creativecommons.org/publicdomain/zero/1.0/) applies to the data made available in this article, unless otherwise stated in a credit line to the data. 


\begin{abstract}
(Continued from previous page)
Conclusions: The results of The WSES COVID-19 emergency surgery survey are alarming. The combination of an estimated decrease in numbers of emergency surgical patients and an observed increase in more severe septic diseases may be a result of the fear of patients from infection with COVID-19 and a consecutive delayed hospital admission and diagnosis. A critical delay in time-to-diagnosis and time-to-intervention may be a result of changes in in-hospital logistics and operating room as well as intensive care capacities. Both reflect the potentially harmful impact of SARS-CoV-2 pandemic on emergency surgery services.
\end{abstract}

Keywords: COVID-19, SARS-CoV-2, Emergency surgery, Appendicitis, Cholecystitis, WSES

\section{Background}

Since the World Health Organization declared SARSCoV-2 as a worldwide pandemic in early 2020, the disease majorly influences political decisions, social life and especially health care services as well as daily therapeutic practices [1-6]. Recommendations from politics as well as respective medical societies aimed to postpone elective therapies, especially elective surgery aimed primarily to hold up bed, intensive care as well as operating room capacities available during the pandemic $[3,7-10]$. The second goal was certainly to preserve patients from nosocomial infection with COVID-19 [9]. Respective statements, how to proceed with those patients, had been published for oncologic therapy and cancer surgery $[1,2,11-13]$. Thereby, it is known that especially cancer patients are highly vulnerable for COVID-19 but a delay in cancer-specific therapy might cause severely impaired oncologic outcome $[1,2,11-13]$. Balancing the necessity of SARS-CoV-2 measures on the one hand and the urgent treatment of surgical emergency patients on the other hand made the SARS-CoV-2 pandemic an everyday challenge for emergency surgery worldwide. Since the rapid spread of the SARS-CoV-2 around the world in late 2019, a high amount of research had been published regarding the pandemic and the characteristics of COVID-19 disease, but only very little is known about the impact of the pandemic's consequences on clinical daily routine in emergency surgery. Several structural changes were established in hospitals around the world to deal with (potentially) high numbers of severely and critically ill patients infected with COVID-19 [2-5]. There are the risk and the fear of patients of getting infected with SARS-CoV-2 and suffering from severe course of COVID-19 [14]. Undoubtedly, all of these factors not only influence the entire spectrum of elective patient care but also might have a significant impact on daily routine patient care in emergency rooms and in particular emergency surgery around the world. Therefore, The WSES COVID-19 emergency surgery survey investigates the impact of the SARS-CoV-2 pandemic on patients and their diseases requiring emergency surgery and on time-to-diagnosis and time-to-intervention in emergency departments as well as the causes for a delayed surgical therapy, following the aim to improve emergency surgical patient care during the pandemic.

\section{Methods}

An online survey was designed by a core group of investigators of the study. Google Forms (Google LLC, Mountain View, CA, USA) was used as the platform for the survey.

The survey consists of 16 single-choice items and one open-answer question. The items are organized in five sections: (1) recording the characteristics of collaborators and their affiliated hospitals-three items, (2) investigating the impact of SARS-CoV-2 pandemic on patients requiring emergency surgery-three items, (3) septic diseases requiring emergency abdominal surgery-three items, (4) structural problems driven by the pandemic and leading to a delayed emergency surgical treatment-six items, and, finally, (5) the experiences of the study group with emergency surgery in COVID-19-infected patients assessed by one item and one open-answer question.

After the survey was approved by the World Society of Emergency Surgery (WSES) project steering committee, it was distributed to the multi-national mailing list of WSES members on June 9, 2020. The deadline to participate was June 26, 2020. After closing the survey, the results were checked for duplicates. Results are presented descriptively within the present manuscript. All 17 items of the survey as well as the assignment of items to figures in the present manuscript are depicted in Table 1.

\section{Results}

\section{Characteristics of the participants}

Ninety-eight members of the WSES from 31 countries around the world and four continents, respectively, responded to the survey (see Table 2). Most of the participants were health care specialists, including board-certified surgeons, senior consultants and heads of their department (see Fig. 1). Among them, 11 (11.2\%) participants stated that their hospital does not treat any patients suffering from COVID-19 and, vice versa, emergency surgery was suspended in hospitals of 5 (5.1\%) participants of the survey during the SARS-CoV-2 pandemic (see Fig. 2). The answers of participants, whose hospitals did not treat COVID-19 patients, are indicated in the figures. 
Table 1 Assignment of the 17-item questionnaire to answers of the survey and results of the manuscript. OR = operating room. $\mathrm{ICU}=$ intensive care unit

\begin{tabular}{|c|c|c|}
\hline Figure & Item & Answer \\
\hline Fig. 1 & What is your current position? & $\begin{array}{l}\text { - Resident } \\
\text { - Board-certified surgeon } \\
\text { - Senior consultant } \\
\text { - Head of the department }\end{array}$ \\
\hline \multirow[t]{2}{*}{ Fig. 2} & $\begin{array}{l}\text { a: In general, does your hospital } \\
\text { treat COVID-19 patients? }\end{array}$ & $\begin{array}{l}\text { - Yes } \\
\text { - No }\end{array}$ \\
\hline & $\begin{array}{l}\text { b: Have you continued to treat } \\
\text { surgical emergency patients } \\
\text { during the SARS-Co-2 } \\
\text { pandemic? }\end{array}$ & $\begin{array}{l}- \text { Yes } \\
\text { - No }\end{array}$ \\
\hline Fig. 3 & $\begin{array}{l}\text { Has the SARS-Co- } 2 \text { pandemic } \\
\text { had any impact on the treat- } \\
\text { ment of surgical emergency } \\
\text { patients? }\end{array}$ & $\begin{array}{l}\text { - No impact } \\
\text { - Weak impact } \\
\text { - Moderate impact } \\
\text { - Strong impact } \\
\text { - Very strong impact }\end{array}$ \\
\hline \multirow[t]{2}{*}{ Fig. 4} & $\begin{array}{l}\text { Has there been a decrease in } \\
\text { the number of surgical } \\
\text { emergency patients entering } \\
\text { your hospital? }\end{array}$ & $\begin{array}{l}- \text { Yes } \\
\text { - No }\end{array}$ \\
\hline & If so, to what degree? & $\begin{array}{l}-<10 \% \\
-10-20 \% \\
-21-40 \% \\
-41-60 \% \\
-61-80 \% \\
-81-100 \%\end{array}$ \\
\hline \multirow[t]{4}{*}{ Fig. 5} & $\begin{array}{l}\text { a: Has there been a delay in the } \\
\text { time from entering the hospital } \\
\text { (e.g. with an intestinal } \\
\text { perforation) to the diagnosis } \\
\text { ("time-to-diagnosis")? }\end{array}$ & $\begin{array}{l}\text { - Yes } \\
\text { - No }\end{array}$ \\
\hline & $\begin{array}{l}\text { If so, please, estimate the delay, } \\
\text { e.g. from entering the hospital } \\
\text { until the timepoint of CT-scan. }\end{array}$ & $\begin{array}{l}-<0.5 h \\
-0.5-1 h \\
-1-2 h \\
-2-3 h \\
->3 h\end{array}$ \\
\hline & $\begin{array}{l}\text { b: Has there been a delay in } \\
\text { the time-from-diagnosis (e.g. of } \\
\text { an intestinal perforation in the } \\
\text { CT-scan) to the beginning of } \\
\text { surgical intervention ("time-to- } \\
\text { intervention")? }\end{array}$ & $\begin{array}{l}\text { - Yes } \\
\text { - No }\end{array}$ \\
\hline & $\begin{array}{l}\text { If so, to which degree? The } \\
\text { time-to-intervention was }\end{array}$ & $\begin{array}{l}-<0.5 \mathrm{~h} \text { longer } \\
-1-2 \mathrm{~h} \text { longer } \\
-2-3 \mathrm{~h} \text { longer } \\
->3 \mathrm{~h} \text { longer }\end{array}$ \\
\hline Fig. 6 & $\begin{array}{l}\text { What, do you think, are the } \\
\text { most important factors, leading } \\
\text { to an enlarged time-to- } \\
\text { intervention? }\end{array}$ & $\begin{array}{l}\text { - Lack of ICU capacity } \\
\text { - Less OR capacity } \\
\text { - Lack of OR staff } \\
\text { - Worse in-hospital logistics } \\
\text { (e.g. transport of patients, } \\
\text { closed normal wards, etc.) }\end{array}$ \\
\hline Fig. 7 & $\begin{array}{l}\text { Has there been the need of a } \\
\text { triage of emergency patients } \\
\text { due to limited capacities during } \\
\text { the COVID-19 pandemic? }\end{array}$ & $\begin{array}{l}\text { - Yes } \\
\text { - No }\end{array}$ \\
\hline Fig. 8 & $\begin{array}{l}\text { Did you observe an increased } \\
\text { relative number of perforated } \\
\text { appendicitis during the COVID- } \\
\text { 19-pandemic? }\end{array}$ & $\begin{array}{l}- \text { Yes } \\
\text { - No }\end{array}$ \\
\hline
\end{tabular}

Table 1 Assignment of the 17-item questionnaire to answers of the survey and results of the manuscript. OR = operating room. ICU = intensive care unit (Continued)

\begin{tabular}{lll}
\hline Figure & Item & Answer \\
\hline & Did you observe an increased & - Yes \\
relative number of perforated & - No \\
diverticulitis during the COVID- & \\
19-pandemic? & \\
& $\begin{array}{l}\text { Did you observe an increased } \\
\text { relative number of severe septic } \\
\text { cholecystitis during the COVID- }\end{array}$ & \\
19-pandemic? & \\
Table & $\begin{array}{l}\text { Did you perform emergency } \\
\text { surgery in patients infected }\end{array}$ & - Yes \\
with COVID-19? & - No \\
Which emergency operation & Open answer \\
did you perform in patients & \\
with COVID-19? & \\
\hline
\end{tabular}

\section{Impact of SARS-CoV-2 pandemic on capacities for emergency surgery}

The majority of participants estimate the impact of the SARS-CoV-2 pandemic on emergency surgical patient care as being strong or very strong ( $n=64$, i.e. $65.3 \%)$. Notably, even seven participants working in those hospitals, where no COVID-19 patients were treated, also estimated the impact of the pandemic on emergency surgical patient care as being strong or very strong (see Fig. 3).

To evaluate the reasons why the SARS-CoV-2 pandemic impacts on emergency surgery, the collaborators of the study group were asked for factors being critical in the therapy of emergency surgical patients during the pandemic: general caseload in emergency surgery, diagnostic ("time-to-diagnosis"), therapeutic ("time-to-intervention") and intensive care capacities in their respective hospitals. Therefore, most of the participants reported a decrease in the total number of patients undergoing emergency surgery in their hospitals $(n=86$, i.e. $87.8 \%)$ to a reduction ranging between 21 and $60 \%$ of the cases in $54.7 \%$ of their hospitals during the pandemic (see Fig. 4).

In the emergency room workflow, no delay in the time-to-diagnosis was stated by $58(59.2 \%)$ of the

Table 2 Working-continents of The WSES COVID-19 emergency surgery survey collaboration group

\begin{tabular}{ll}
\hline Continent & ( $\boldsymbol{n}$ ) participants \\
\hline Europe & 60 \\
America & 12 \\
Asia & 23 \\
Africa & 3 \\
\hline
\end{tabular}




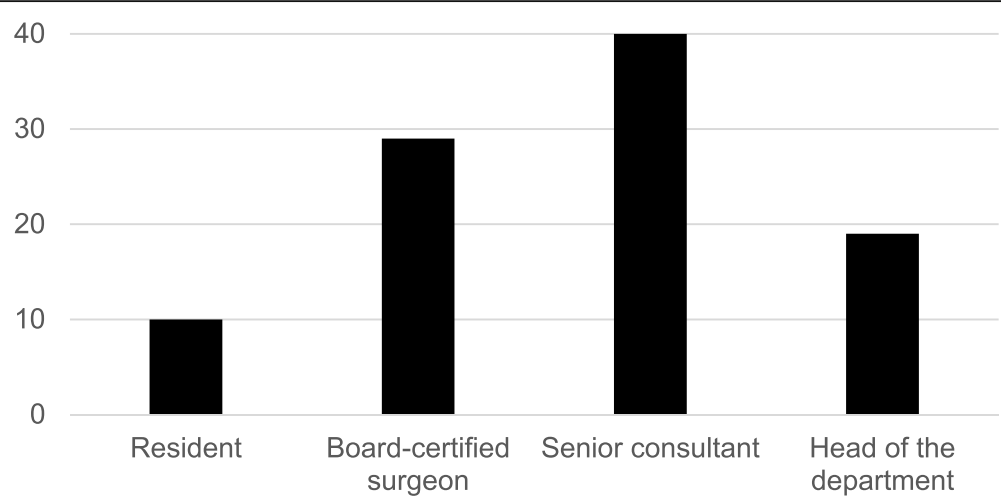

Fig. 1 Qualification and position of the participants of The WSES COVID-19 emergency surgery survey

In general, does your hospital treat COVID-19 patients?

a

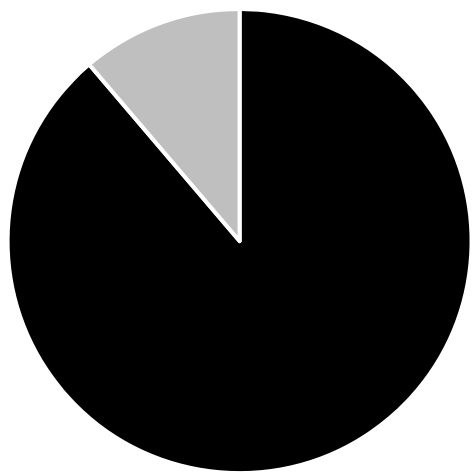

Have you continued to treat surgical emergency patients?

b

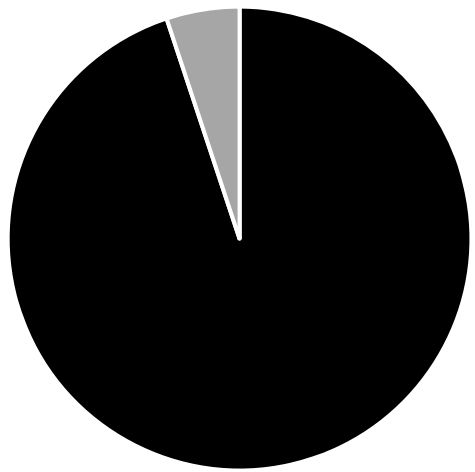

Fig. 2 Patient treatment during the SARS-CoV-2 pandemic. a In general, does your hospital treat COVID-19 patients? Answers: "Yes" in black ( $n=87$, i.e. $88.8 \%$ ) and "No" in grey $(n=11$, i.e. $11.2 \%)$. b Have you continued to treat surgical emergency patients during the SARS-CoV-2 pandemic? Answers: "Yes" in black ( $n=93$, i.e. 94.9\%) and "No, patients were transferred to other hospitals" in grey $(n=5$, i.e. $5.1 \%)$ participants, whereas one-fourth of the study group estimated a dramatical delay of more than $2 \mathrm{~h}$ in time-todiagnosis by a computed tomography from entering the hospital for critical ill surgical patients (see Fig. 5 a). The same holds true for the time from diagnosis to intervention. Therefore, a critical delay of even more than $2 \mathrm{~h}$ was estimated in hospitals of almost one-fourth of the study group during the SARS-CoV-2 pandemic for patients requiring any emergency surgical intervention (see Fig. 5 b). Beneath a lack of operating room staff $(n=7$, i.e. $7.1 \%)$ and operating room as well as intensive care unit capacities $(n=15$, i.e. $15.3 \%$ as well as $n=12$, i.e. $12.2 \%$, respectively), structural problems with in-hospital logistics (e.g. transport of patients, closed normal wards etc.) were seen as the most important factors for a delay in surgical emergency patient treatment from $50 \%$ of the study group ( $n=49$, see Fig. 6). All of those structural problems and limited capacities culminate in the urgent need for a triage of emergency surgical patients reported by $55(56.1 \%)$ participants of the study group, which may furthermore worsen the resources of surgical emergency patient care during the SARS-CoV-2 pandemic (see Fig. 7).

\section{Impact of SARS-CoV-2 pandemic on diseases requiring emergency surgery}

The study group was asked for their subjective observation, if a higher severity was more prevalent during the SARS-CoV-2 pandemic in patients suffering from frequent septic diseases requiring abdominal emergency surgery, including appendicitis, cholecystitis and diverticulitis. Overall, $56.1 \%$ of the study group observed more severe septic abdominal diseases during the pandemic, especially for appendicitis and cholecystitis (41.8\% and $40.2 \%$ of the study group, respectively), which make a rapid time-to-surgical-intervention mandatory (see Fig. 8). Interestingly, even 7 (63.6\%) collaborators from hospitals, where no COVID-19 patients 


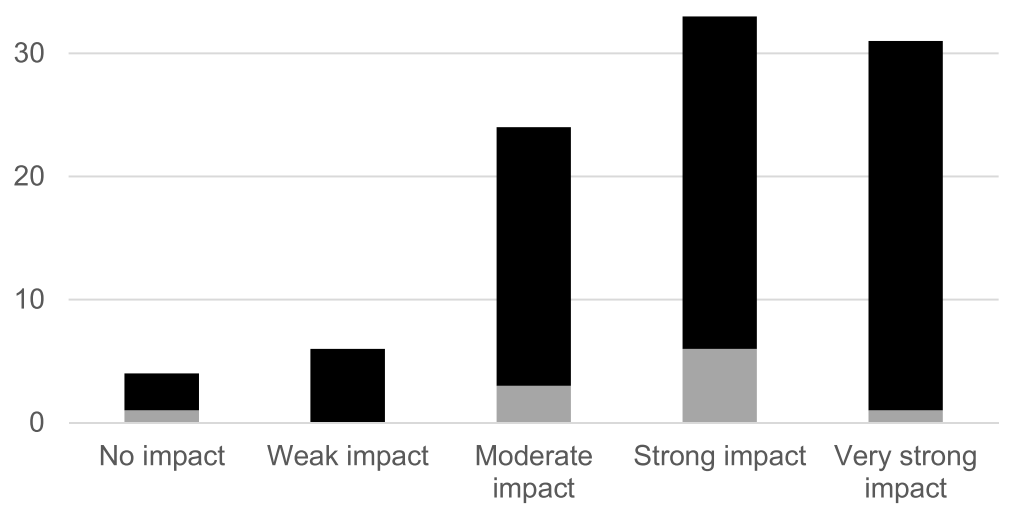

Fig. 3 Has the SARS-CoV-2 pandemic had any impact on the treatment of surgical emergency patients? Estimates by the collaborators from "No impact" to "Very strong impact". Participants, whose hospitals were not involved in COVID-19 patient care, are depicted in grey

were treated, observed this trend. Finally, the majority of participants $(n=61$, i.e. $62.2 \%)$ performed any kind of emergency surgery in patients infected with COVID-19. Thereby, the study group had the most experiences with appendectomies, cholecystectomies and laparotomies for trauma, intestinal perforation and any kind of bowel resection (see Table 3).

\section{Discussion}

This study proves a severe impact of the SARS-CoV-2 pandemic situation and it's consequences on emergency surgical patient care around the world. Interestingly, even collaborators from hospitals, where no COVID-19 patients were treated described that the pandemic at least strongly affects their emergency surgical patient care. In the opposite to elective medical treatment or elective (oncologic) surgery, emergencies do frequently not tolerate even small postponement; otherwise, the disease rapidly progresses, gets more severe, more complicated and potentially ends fatal.

The study group observed on the one hand a lower number of patients who underwent emergency surgical procedures, but on the other hand a higher rate of perforated or more severe septic abdominal diseases in patients conducted to emergency surgery. A decrease in absolute numbers of patients with surgical complaints in the emergency department during the SARS-CoV-2 pandemic had been previously described [15-17]. This might be an effect of the worldwide lockdown policies as well as the fear of the patients from COVID-19 and might result in delayed diagnosis and therapy. Also Snapiri et al. observed a high rate of complicated appendicitis with abscess or perforation in their patient cohort during the pandemic [14]. They discussed changes in medical evaluation and decision-making processes of the patients, their relatives and treating physicians as

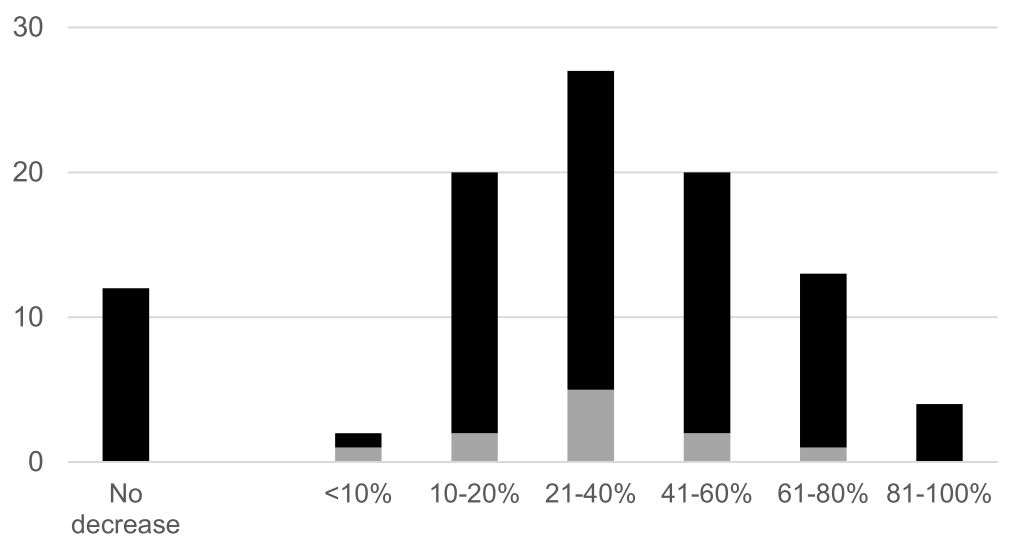

Fig. 4 Has there been a decrease in the number of surgical emergency patients entering your Hospital? If the participants reported a decrease, they were also asked to estimate the degree of the decrease in percentage in their hospital. Note that also surgical emergency care givers from hospitals, where no COVID-19 patients were treated regularly, reported a decrease of emergency surgical caseload. Participants, whose hospitals were not involved in COVID-19 patient care, are depicted in grey 

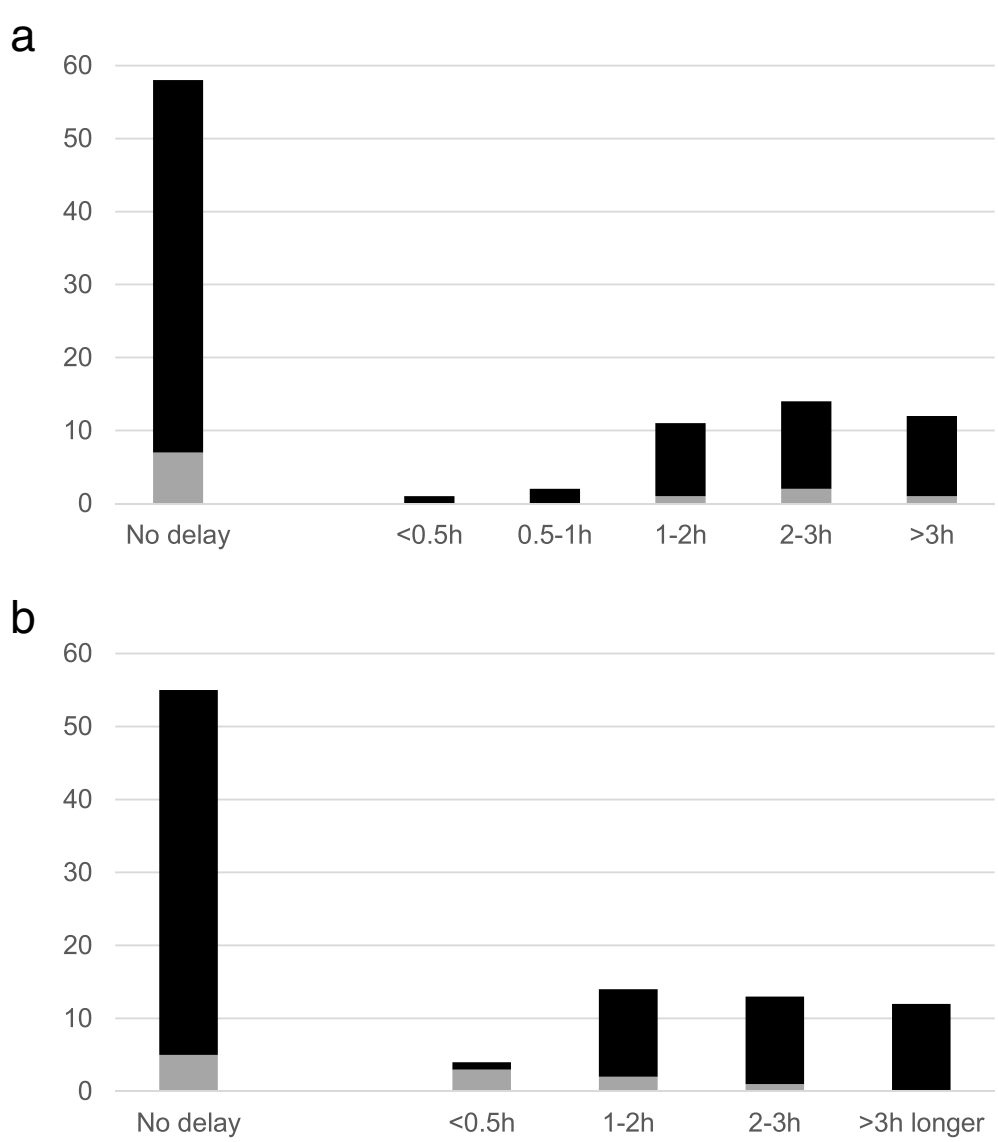

Fig. 5 Impact of the SARS-Co-2 pandemic on "time-to-diagnosis" and "time-to-intervention" in surgical emergency patients. Participants, whose hospitals were not involved in COVID-19 patient care, are depicted in grey. a Has there been a delay in the time from entering the hospital (e.g. with an intestinal perforation) to the diagnosis ("time-to-diagnosis")? If the participants reported a delay, they were also asked to estimate the delay, e.g. from entering the hospital until the timepoint of computer tomography. $\mathbf{b}$ Has there been a delay in the time-from-diagnosis (e.g. of an intestinal perforation in the CT-scan) to the beginning of surgical intervention ("time-to-intervention")? If the participants reported a delay, they were also asked to estimate the delay from diagnosis to surgical intervention

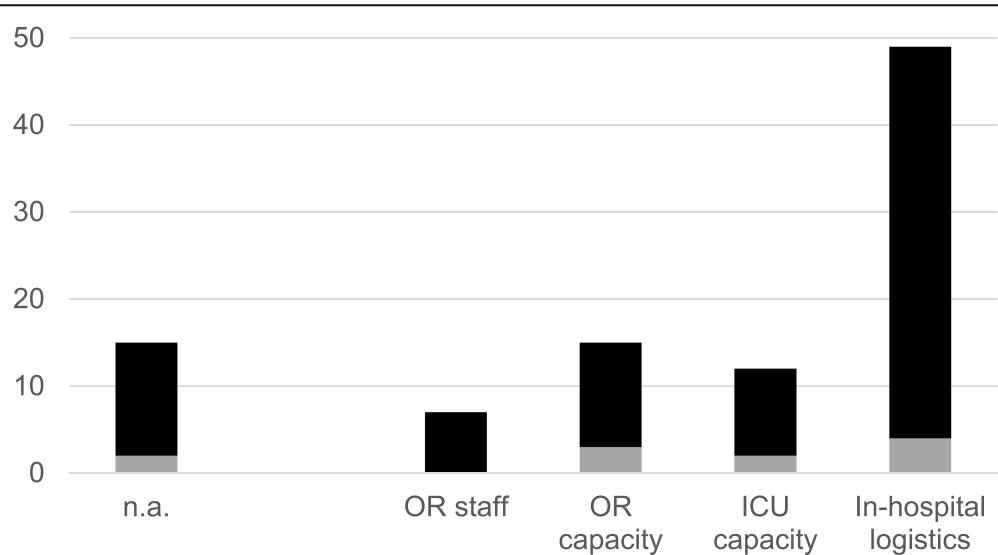

Fig. 6 The most important factor, leading to an enlarged time-to-intervention during the SARS-CoV-2 pandemic. Participants, whose hospitals were not involved in COVID-19 patient care, are depicted in Grey. n.a. = no answer. Lack in OR (operating room) staff, OR capacities and ICU (intensive care unit) capacities were stated as the reasons for a delay in time-to-intervention by $7.1 \%, 15.3 \%$ and $12.2 \%$ of the responders, respectively. Notably, problems with in-hospital logistics (e.g. transport of patients, closed normal wards et cetera) were seen as the most important factors for a delayed time-to-intervention in surgical emergency patients by the majority (50\%) of the participants 
Need of triage of emergency patients during the pandemic?

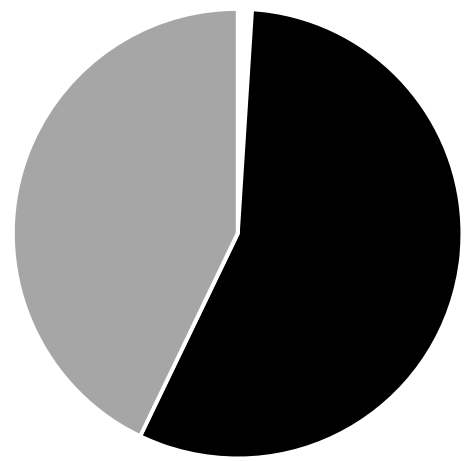

Fig. 7 Has there been the need of a triage of emergency patients due to limited capacities during the SARS-CoV-2 pandemic?

Answers: "Yes" in black ( $n=55$, i.e. $56.1 \%)$ and "No" in grey $(n=42$, i.e. $42.9 \%)$. No answer was given by one participant

possible reasons for a diagnosis in later stages of the disease [14]. Thereby it is well known that complications frequently occur as late as $36-48 \mathrm{~h}$ after onset of symptoms of acute appendicitis [14, 18-21]. As discussed by Patriti et al., the negative impact of the SARS-CoV-2 pandemic on surgical activities is multifactorial [16]. Results of their survey among local surgeons during the SARS-CoV-2 outbreak in Italy remained that changing daily practice, shifting working plans, and reduction in personnel resources through allocating surgeons to non-surgical departments, high sickness and quarantine rates among surgeons during the pandemic led to a lower quality of surgical patient care [16]. Furthermore, the diffuse symptomatology of COVID-19 patients including gastrointestinal symptoms and abdominal pain, reported in the current literature, may disguise the real cause and may delay the adequate (surgical) therapy of affected patients during the pandemic
$[22,23]$. As for patients with delayed diagnosed appendicitis, the same might be true for cholecystitis and diverticulitis. Nevertheless, the COVIDSurg Collaborative recently described a high rate of mortality and pulmonary complications in patients undergoing surgery with perioperative SARS-CoV-2 infection [24]. These results led the COVIDSurg Collaborative to their conclusion that preventively postponing of non-urgent surgical procedures or non-operative treatment options should be considered [24]. However, several diseases presenting in the emergency department require urgent or emergency surgical therapy; thus, among others, Campanile et al. declare in their multi-society position statement the laparoscopic cholecystectomy still as the therapeutic standard-of-care in patients with acute cholecystitis even in the SARSCoV-2 pandemic situation [25].

The long delay (more than $2 \mathrm{~h}$ ) in time-to-diagnosis and furthermore in time-to-intervention observed in emergency situations by approximately one-fourth of the participants during the SARS-CoV-2 pandemic are the most critical results of the present study. Unfortunately, these items of the survey were kept very generally; thus, the underlying diseases, for which the delays were estimated and if there are differences, e.g. in trauma or septic patients, were not the objective of the survey. However, the responses of The WSES COVID-19 emergency surgery survey collaboration group give important implications on the structural problems and barriers, which emergency surgeons and their patients are faced with. The COVID-19 outbreak severely impairs our society, health care systems and especially in-hospital infrastructure; barriers arising from extensive preventive measures during the pandemic situation might by an underlying cause for processing emergency patients into routine diagnostic and therapeutic pathways $[6,10]$. Nevertheless, a rapid surgical

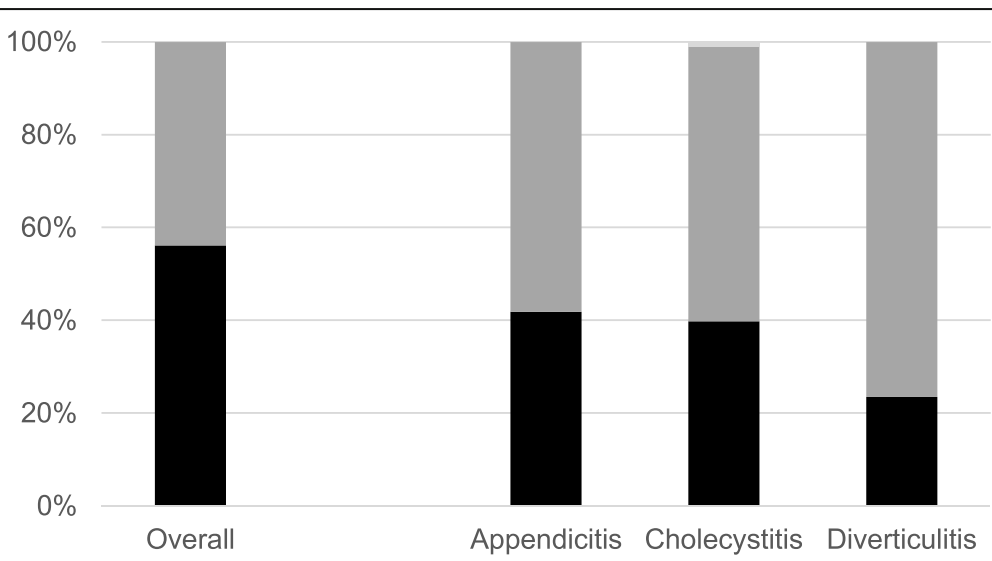

Fig. 8 Did you observe an increased relative number of perforated appendicitis/perforated diverticulitis/severe septic cholecystitis during the SARS-CoV-2 pandemic? Overall, 56.1\% of the study group subjectively observed more severe septic abdominal diseases during the SARS-CoV-2 pandemic. Answers: "Yes" in black and "No" in grey. No answer was given by one participant regarding the relative number of severe septic cholecystitis during the SARS-CoV-2 pandemic (depicted in white) 
Table 3 Experiences with emergency surgery in COVID-19 positive patients given by the study group

\begin{tabular}{|c|c|c|c|c|c|c|}
\hline $\begin{array}{l}\text { Type of emergency surgery } \\
\text { in COVID-19-positive patients }\end{array}$ & Appendectomy & Cholecystectomy & $\begin{array}{l}\text { Incarcerated } \\
\text { hernia repair }\end{array}$ & $\begin{array}{l}\text { Laparotomy } \\
\text { for trauma }\end{array}$ & $\begin{array}{l}\text { Soft tissue } \\
\text { infection }\end{array}$ & Tracheostomy \\
\hline (n) participants & $27(27.6 \%)$ & $11(10.2 \%)$ & $7(7.1 \%)$ & $10(10.2 \%)$ & $3(3.1 \%)$ & $2(2.0 \%)$ \\
\hline $\begin{array}{l}\text { Type of bowel emergency } \\
\text { surgery in COVID-19-positive } \\
\text { patients }\end{array}$ & $\begin{array}{l}\text { Intestinal } \\
\text { perforation }\end{array}$ & $\begin{array}{l}\text { Mesenteric } \\
\text { ischemia }\end{array}$ & $\begin{array}{l}\text { Sigmoid } \\
\text { volvulus }\end{array}$ & Ileus & $\begin{array}{l}\text { Hartmann's } \\
\text { procedure }\end{array}$ & $\begin{array}{l}\text { Other type of / } \\
\text { other indication } \\
\text { for bowel resection }\end{array}$ \\
\hline (n) participants & 11 (10.2\%) & 3 (3.1\%) & $1(1.0 \%)$ & $2(2.0 \%)$ & $4(4.1 \%)$ & $11(11.2 \%)$ \\
\hline
\end{tabular}

therapy is mandatory for a high percentage of acute care patients, including trauma and septic diseases, still in the pandemic situation $[15,26]$. It is well known that delayed emergency surgery results in high morbidity rates and worsens survival for the patients, whereby the risk of death increases per hour [26, 27]. Furthermore, The WSES COVID-19 emergency surgery survey study group, consisting of specialists in emergency surgery around the world, estimates the most important factors, leading to the critical impairment in diagnostic and therapeutic work-up of emergency surgical patients. The present study proves that this is not a local but more of a worldwide issue. To solve these problems and to improve emergency surgical patient care during the pandemic, policies, respective medical societies and local health care providers should define tailored solutions and provide resources to enhance medical staff, operating room capacities, intensive care capacities and-in particular-in-hospital logistics.

Although The WSES COVID-19 emergency surgery survey collaboration group consists of some highly experienced and specialized associates in emergency surgery, the study has some strong limitations. The collected data presented in this present work are based on subjective feelings, observations and estimations of the collaboration group. Thus a "hard" data basis, e.g. by big data analysis during the SARS-CoV2 pandemic, is currently lacking. Furthermore, data were collected in a small period of time, in which parts of the world were currently suffering from SARS-CoV-2 outbreaks, whereas others were beyond the outbreak. However, the estimation about the impact of the pandemic on emergency surgery was homogenous.

\section{Conclusions}

The results of The WSES COVID-19 emergency surgery survey are alarming. An estimated decrease in numbers of emergency surgical patients and an observed increase in more severe septic diseases may be a result of the fear of patients from infection with COVID-19 and a consecutive delayed hospital admission and diagnosis. A critical delay in time-to-diagnosis and time-to-intervention may be a result of changes in in-hospital logistics and operating room as well as intensive care capacities. Both reflect the potentially harmful impact of SARS-CoV-2 pandemic on emergency surgery services. Based on these investigations, further measures are necessary to develop optimized clinical pathways for a reduction in the time-to-diagnosis and time-to-intervention in emergency departments around the world. These should aim not only to prevent medical staff as well as emergency surgical patients from infection with COVID-19 and to protect infected patients from a perioperative exacerbation of the disease with consecutive severe morbidities and mortality $[9,24]$, but also to prevent the need for triage of emergency surgical patients and to provide a timely surgical therapy in all (infected or non-infected) urgent and emergency patients.

The WSES supports all efforts to fight for an optimized treatment of our surgical emergency patients both in cases of local COVID-19 outbreak and also the worldwide setting!

\section{Abbreviation}

WSES: World Society of Emergency Surgery

\section{Acknowledgements}

The authors sincerely thank all collaborators of the study for participation in the survey.

The WSES COVID-19 emergency surgery survey collaboration group: Abakar Abdullaev, Department of Abdominal Surgery, Vladimir City Emergency Hospital, Vladimir, Russia

Adrian Camacho-Ortiz, Hospital Universitario Dr. José Eleuterio Gonzalez, Mexico

Adriana Toro, General Surgery, Augusta Hospital, Augusta (SR), Italy

Alain Chichom-Mefire, Faculty of Health Sciences, University of Buea, Cameroon

Aleix Martínez-Pérez, Department of General and Digestive Surgery, Doctor Peset University Hospital, Valencia, Spain

Alfie J Kavalakat, Jubilee Mission Medical College \& Rl, Thrissur, India Ali Yasen Y Mohamedahmed, General Surgery, Sandwell General Hospital, Birmingham, UK

Andrey Litvin, Department of Surgical Disciplines, Immanuel Kant Baltic Federal University, Regional Clinical Hospital, Kaliningrad, Russia

Antonio Brillantino, Department of Surgery, A. Cardarelli Hospital, Naples, Italy Antonio Pesce, Policlinico Abano Terme, Padua, Italy

Arda Isik, General Surgery Department, Erzincan University Hospital, Erzincan, Turkey

Aristotelis Kechagias, Department of Gastrointestinal Surgery, Kanta-Häme Central Hospital, Hämeenlinna, Finland

Azzain M H Ismail, Department of Trauma \& Orthopaedics, Aberdeen Royal Infirmary, Aberdeen, UK

Baris Mantoglu, General Surgery, Sakarya University Educating and Research Hospital, Sakarya, Turkey

Basil Ibrahim, Speciality Registrar in Colorectal surgery, University hospital of north Durham, UK

Birgit Hecker, Department of Anesthesiology, St. Josefs Hospital, Gießen, Germany 
Boris Sakakushev, Research Institute at Medical University Plovdiv, University Hospital St George, Plovdiv, Bulgaria

Charalampos Seretis, George Eliot Hospital NHS Trust, UK

Dimitrios Manatakis, Department of Surgery, Athens Naval and Veterans

Hospital, Athens, Greece

Edgar Fernando Hernández García, Cirugía General y Laparoscópica, Cirugía

de trauma, Hospital Central Militar, Mexico

Elif Çolak, University of Health Sciences Turkey, Samsun Training and

Research Hospital, Turkey

Elmin Steyn, Division of Surgery, Tygerberg Hospital, Stellenbosch University, South Africa

Emrah Akin, Department of General Surgery, Sakarya University Educating and Research Hospital, Sakarya, Turkey

Emre Gonullu, General Surgery, Sakarya University Educating and Research Hospital, Sakarya, Turkey

Fabio Cesare Campanile, General Sugery, San Giovanni Decollato /Andosilla

Hospital, Civita Castellana VT, Italy

Francesco Pata, Department of Surgery, Nicola Giannettasio Hospital,

Corigliano-Rossano, Italy

Francesco Roscio, Department of General Surgery, ASST Valle Olona, Busto

Arsizio, Italy

Fredrik Linder, Gävle county Hospital, Gävle, Sweden

Gia Tomadze, Surgery Department, Tbilisi State Medical University, Tiblisi, Georgia

Gianluca Pellino, Colorectal Surgery, Vall d'Hebron University Hospital,

Barcelona, Spain

Gianmaria Casoni Pattacini, Department of General Surgery, Emergencies and New Technologies, Baggiovara Civil Hospital, Modena, Italy

Giovanni Pirozzolo, Dell'Angelo Hospital, Venice, Italy

Gustavo M. Machain, Jefe de Catedra y Servicio de Cirugia General, II Catedra,

Hospital de Clinicas, FCM, Universidad Nacional de Asuncion, Paraguay

Gustavo P. Fraga, School of Medical Sciences (SMS), University of Campinas

(Unicamp), Campinas, Brazil

Hazim Abdulnassir Eltyeb, St4 General Surgery, Northumbria Healthcare NHS

Foundation Trust, UK

loannis Nikolopoulos, Lewisham and Greenwich NHS Trust

Isidoro Di Carlo, Department of Surgical Sciences and Advanced

Technologies, General Surgery, University of Catania, Cannizzaro Hospital,

Catania, Italy

Jae II Kim, Department of Surgery, Inje University Ilsan Paik Hospital, Goyang,

South Korea

Jesus-Manuel Saenz-Terrazas, Weapon Traumatology and Training Center,

Dar Al-Chifae Hospital, Tripoli, Lebanon

Juan Carlos Rodriguez Sanjuan, Jefe de Servicio de Cirugía General, Hospital

Universitario Marqués de Valdecilla (Santander), Universidad de Cantabria,

Santander, Spain

Juliane Liese, Department of General, Visceral, Thoracic, Transplant and

Pediatric Surgery, University Hospital of Giessen, Giessen, Germany

Justin Davies, Cambridge Colorectal Unit, Addenbrooke's Hospital,

Cambridge University Hospitals NHS Foundation Trust, Cambridge, UK

Kim Platte, Ziekenhuis Amstelland, Amstelveen, Netherlands

Lawrence Lottenberg, Department of Surgery, Florida Atlantic University

Charles E. Schmidt College of Medicine, Boca Raton, FL, USA

Leonardo Pagani, Antimicrobial Stewardship Program, Infectious Diseases

Unit, Bolzano Central Hospital, Bolzano, Italy

Leonardo Solaini, General and Oncologic Surgery, Morgagni-Pierantoni Hospital, Forli, Italy

Lisa Miller, Western Michigan University Homer Stryker MD School of

Medicine, USA

Lovenish Bains, Department of Surgery, Maulana Azad Medical College, New Delhi, India

Luis Buonomo, Hospital "Dr. Alberto Balestrini", University of Buenos Aires, Argentina

Maciej Walędziak, Department of General, Oncological, Metabolic and

Thoracic Surgery, Military Institute of Medicine, Warsaw, Poland

Mahir Gachabayov, Department of abdominal surgery, Vladimir City

Emergency Hospital, Vladimir, Russia

Marc Maegele, Department of Trauma and Orthopedic Surgery, Institute for Research in Operative Medicine (IFOM), Cologne-Merheim Medical Center (CMMC), University Witten/Herdecke, Campus Cologne-Merheim, Cologne, Germany
Marco Catarci, General Surgery Unit, C.e G. Mazzoni Hospital, Ascoli Piceno, Italy

Marco Vittorio Rossi Ardizzone, Italy

Maria Grazia Alberio, Chirurgia generale d'urgenza, Ospedale di circolo -

Varese, Italy

Massimiliano Veroux, General Surgery and Organ Transplant Unit, Azienda

Policlinico University of Catania, Catania, Italy

Matteo Nardi, S. Giovanni Calibita Hospital-Fatebenefratelli Foundation, Rome,

Italy

Mauro Podda, Department of Emergency Surgery, Cagliari University

Hospital, Cagliari, Italy

Michael Sugrue, Department of Surgery, Letterkenny University Hospital and

Centre for Personalised Medicine, Donegal, Ireland

Michele Pisano, General Surgery Unit, ASST Papa Giovanni XXIII, Bergamo,

Italy

Mihail Slavchev, Department of General Surgery, University Hospital

Eurohospital, Plovdiv, Bulgaria

Mika Ukkonen, Department of Surgery, Tampere University Hospital,

Tampere, Finland

Miklosh Bala, Trauma and Acute Care Surgery Unit, Hadassah - Hebrew

University Medical Center, Jerusalem, Israel

Mircea Chirica, Department of Digestive Surgery, Centre Hospitalier

Universitaire Grenoble Alpes, Grenoble, France

Mouaqit Ouadii, Hassan II Hospital, Fes, Morocco

Orestis Ioannidis, 4th Surgical Department, Medical School, Aristotle

University of Thessaloniki, Thessaloniki, Greece

Osvaldo Chiara, Trauma and Emergency Surgery, University of Milan, Milan, Italy

Pankaj Kumar, Department of General Surgery, Bhubaneswar,Odisha, India

Per Örtenwall, Department of Surgery, Sahlgrenska University Hospital,

Gothenburg, Sweden

Pradeep Navsaria, Trauma Center, Groote Schuur Hospital, University of Cape Town, Cape Town, South Africa

Raul Coimbra, Surgery, Loma Linda University School of Medicine, Riverside University Health System, Riverside, USA

Riccardo Somigli

Robert G. Sawyer, Western Michigan University Homer Stryker School of

Medicine, Kalamazoo, Michigan, USA

Saad Shebrain, Western Michigan University Homer Stryker MD School of

Medicine, Kalamazoo, Michigan, USA

Salomone Di Saverio, Surgery 1st unit, University Hospital of Varese, Varese, Italy

Sanjay Marwah, PGIMS Rohtak, Rohtak, India

Sergio Zegarra

Shahd Nour, North Bristol NHS Foundation Trust, UK

Shahed Abdelmahmoud

Stefano Magnone, General Surgery, Ospedale Papa Giovanni XXIII, Bergamo, Italy

Syed Muhammad Ali, Acute Care Surgery, Hamad Medical Corporation,

Doha, Qatar

Tadeja Pintar, Abdominal Surgery Department, UMC Ljubljana Medical

Faculty, Ljubljana, Slovenia

Tushar S Mishra, Department of Trauma \& Emergency, All India Institute of

Medical Sciences, Bhubaneswar, Odisha, India

Valentina Tomajer, IRCCS San Raffaele Hospital, Milan, Italy

Varut Lohsiriwat, Department of Surgery, Faculty of Medicine, Siriraj Hospital, Mahidol University, Bangkok, Thailand

Vijay Shivpuje, Yashodhara Superspeciality Hospital, Solapur Maharashtra, India

Vladimir Khokha, City Hospital, Mozyr, Belarus

Yoshiro Kobe, Department of Surgery, Chiba Emergency Medical Center,

Chiba, Japan

Zaza Demetrashvili, Surgery Department, Tbilisi State Medical University, Georgia

\section{Authors' contributions}

Each author made substantial contribution to this article. MR analyzed and interpreted the data and wrote the main parts of the manuscript. MS concepted the study and critically revised the manuscript. MAW gave substantial intelligent content to the questionnaire and interpreted the data. $C D, M H, A R-L$ and FB made substantial contribution to the conception of the 
study, interpreted the data and critically revised the manuscript. IA and WP analyzed the data and drafted the work. $\mathrm{FeC}$ and $\mathrm{FaC}$ are representatives from the WSES steering committee and were involved in the design of the work. They revised the manuscript substantively. AH concepted the study mainly, interpreted the data and substantively revised the manuscript. The authors read and approved the final manuscript.

\section{Funding}

No funding was received for this research. Open Access funding enabled and organized by Projekt DEAL.

\section{Availability of data and materials}

The datasets used and/or analyzed during the current study are available from the corresponding author on reasonable request.

\section{Ethics approval and consent to participate}

Not applicable.

\section{Consent for publication}

Not applicable.

\section{Competing interests}

The authors declare that they have no competing interests.

\section{Author details}

'Department of General, Visceral, Thoracic, Transplant and Pediatric Surgery, University Hospital of Giessen, Giessen, Germany. ${ }^{2}$ Department of Surgery, Macerata Hospital, Macerata, Italy. ${ }^{3}$ Department of Anesthesiology, University Hospital of Heidelberg, Heidelberg, Germany. ${ }^{4}$ Department of Pulmonary and Critical Care Medicine, University Hospital of Giessen and Marburg Lung Center (UGMLC), University Hospital of Giessen, Giessen, Germany. ${ }^{5}$ Department of General, Visceral and Oncologic Surgery, Hospital and Clinics Wetzlar, Wetzlar, Germany. ${ }^{6}$ Department of General, Emergency and Trauma Surgery, Pisa University Hospital, Pisa, Italy. ${ }^{7}$ Department of Emergency Surgery, Parma Maggiore Hospital, Parma, Italy.

\section{Received: 10 September 2020 Accepted: 2 November 2020}

\section{Published online: 09 December 2020}

\section{References}

1. Barbieri L, Talavera Urquijo E, Parise P, Nilsson M, Reynolds JV, Rosati R Esophageal oncologic surgery in SARS-CoV-2 (COVID-19) emergency. Dis esophagus Off J Int Soc Dis Esophagus. 2020;33:doaa028.

2. Kamarajah SK, Markar SR, Singh P, Griffiths EA. The influence of the SARSCoV-2 pandemic on esophagogastric cancer services: an international survey of esophagogastric surgeons. Dis esophagus Off J Int Soc Dis Esophagus. 2020;33(7):doaa054.

3. Grasselli G, Pesenti A, Cecconi M. Critical care utilization for the COVID-19 outbreak in Lombardy, Italy: early experience and forecast during an emergency response. JAMA. 2020;323(16):1545-6.

4. Oba A, Stoop TF, Löhr M, Hackert T, Zyromski N, Nealon WH, et al. Global survey on pancreatic surgery during the COVID-19 pandemic. Ann Surg. 2020;272(2):e87-93.

5. Pellino G, Spinelli A. How coronavirus disease 2019 outbreak is impacting colorectal cancer patients in Italy: a long shadow beyond infection. Dis Colon Rectum. 2020;63:720-2.

6. Coccolini F, Sartelli M, Kluger Y, Pikoulis E, Karamagioli E, Moore EE, et al. COVID-19 the showdown for mass casualty preparedness and management: the Cassandra Syndrome. World J Emerg Surg. 2020;15:26.

7. Diaz A, Sarac BA, Schoenbrunner AR, Janis JE, Pawlik TM. Elective surgery in the time of COVID-19. Am J Surg. 2020;219:900-2.

8. Elizabeth Brindle M, Gawande A. Managing COVID-19 in surgical systems. Ann Surg. 2020;272:e1-2.

9. De Simone B, Chouillard E, Di Saverio S, Pagani L, Sartelli M, Biffl WL, et al. Emergency surgery during the COVID-19 pandemic: what you need to know for practice. Ann R Coll Surg Engl. 2020;102:323-32.

10. Coccolini F, Perrone G, Chiarugi M, Di Marzo F, Ansaloni L, Scandroglio I, et al. Surgery in COVID-19 patients: operational directives. World J Emerg Surg. 2020;15:25

11. Ueda M, Martins R, Hendrie PC, McDonnell T, Crews JR, Wong TL, et al. Managing cancer care during the COVID-19 pandemic: agility and collaboration toward a common goal. J Natl Compr Canc Netw. 2020;18(4): 366-9.https://doi.org/10.6004/jnccn.2020.7560.

12. Wang H, Zhang L. Risk of COVID-19 for patients with cancer. Lancet Oncol. 2020:21:e181.

13. Liang W, Guan W, Chen R, Wang W, Li J, Xu K, et al. Cancer patients in SARS-CoV-2 infection: a nationwide analysis in China. Lancet Oncol. 2020;21: $335-7$.

14. Snapiri O, Rosenberg Danziger C, Krause I, Kravarusic D, Yulevich A, Balla U, et al. Delayed diagnosis of paediatric appendicitis during the COVID-19 pandemic. Acta Paediatr. 2020;109(8):1672-6.

15. Anteby R, Zager Y, Barash Y, Nadler R, Cordoba M, Klang E, et al. The impact of the coronavirus disease 2019 outbreak on the attendance of patients with surgical complaints at a tertiary hospital emergency department. J Laparoendosc Adv Surg Tech A. 2020;30(9):1001-7.

16. Patriti A, Baiocchi GL, Catena F, Marini P, Catarci M. Emergency general surgery in Italy during the COVID-19 outbreak: first survey from the real life. World J Emerg Surg. 2020;15:36.

17. Cozza V, Fransvea P, La Greca A, De Paolis P, Marini P, Zago M, et al. I-ACTS S-COVID-19-the Italian acute care and trauma surgery survey for COVID-19 pandemic outbreak. Updates Surg. 2020;72(2):297-304.

18. Rothrock SG, Skeoch G, Rush JJ, Johnson NE. Clinical features of misdiagnosed appendicitis in children. Ann Emerg Med. United States. 1991 20:45-50.

19. Rothrock SG, Pagane J. Acute appendicitis in children: emergency department diagnosis and management. Ann Emerg Med. United States. 2000;36:39-51.

20. Pepper VK, Stanfill AB, Pearl RH. Diagnosis and management of pediatric appendicitis, intussusception, and Meckel diverticulum. Surg Clin North Am. United States. 2012;92:505-26 vii.

21. St Peter SD, Sharp SW, Holcomb GW 3rd, Ostlie DJ. An evidence-based definition for perforated appendicitis derived from a prospective randomized trial. J Pediatr Surg. 2008:43:2242-5.

22. Jin X, Lian J-S, Hu J-H, Gao J, Zheng L, Zhang Y-M, et al. Epidemiological, clinical and virological characteristics of 74 cases of coronavirus-infected disease 2019 (COVID-19) with gastrointestinal symptoms. Gut. 2020;69:1002-9.

23. Zhou Z, Zhao N, Shu Y, Han S, Chen B, Shu X. Effect of gastrointestinal symptoms in patients with COVID-19. Gastroenterology. 2020;158:2294-7.

24. COVIDSurg Collaborative. Mortality and pulmonary complications in patients undergoing surgery with perioperative SARS-CoV-2 infection: an international cohort study. Lancet. 2020;396(10243):27-38.

25. Campanile FC, Podda M, Arezzo A, Botteri E, Sartori A, Guerrieri M, et al. Acute cholecystitis during COVID-19 pandemic: a multisocietary position statement. World J Emerg Surg. 2020;15:38.

26. Hecker A, Schneck E, Rohrig R, Roller F, Hecker B, Holler J, et al. The impact of early surgical intervention in free intestinal perforation: a time-tointervention pilot study. World J Emerg Surg. 2015;10:54.

27. Boyd-Carson H, Doleman B, Cromwell D, Lockwood S, Williams JP, Tierney $\mathrm{GM}$, et al. Delay in source control in perforated peptic ulcer leads to $6 \%$ increased risk of death per hour: a nationwide cohort study. World J Surg. 2020;44:869-75.

\section{Publisher's Note}

Springer Nature remains neutral with regard to jurisdictional claims in published maps and institutional affiliations.

Ready to submit your research? Choose BMC and benefit from:

- fast, convenient online submission

- thorough peer review by experienced researchers in your field

- rapid publication on acceptance

- support for research data, including large and complex data types

- gold Open Access which fosters wider collaboration and increased citations

- maximum visibility for your research: over $100 \mathrm{M}$ website views per year

At BMC, research is always in progress.

Learn more biomedcentral.com/submissions 